\title{
Conflict analysis in collective decision making at a watershed level: a case study from Morocco
}

\author{
M. Al-Saidi \\ Institute for Technology in the Tropics, \\ Cologne University of Applied Sciences, Germany
}

\begin{abstract}
This study will develop a framework to understand basin plan development as a collective decision making process. It advocates for the use of negotiation and conflict analysis tools to deliberately facilitate such processes. An overview of available tools based on game theory and complexity science will be provided. Using the case study of the basin plan development in Morocco, the underlying conflicts will be illustrated based on an application of the Graph Model for Conflict Analysis.

Keywords: collective decision making, water basins, basin negotiations, integrated water resources management, Morocco.
\end{abstract}

\section{Introduction}

Water sharing conflicts between different users represent a huge challenge for reforming water policies. A wide stakeholder participation and collective decisionmaking via negotiations have emerged as a way to solve these conflicts. In recent years, and under the paradigm of integrated water resources management (IWRM), stakeholder participation has increasingly been suggested as the solution for effective policy-making. Under the IWRM pillar of the 'ecological principle', the role of stakeholder dialogue and cooperation in the development of preparation of policies and legislations is strongly highlighted. Policy-making through negotiated outcomes may increase the efficiency of decisions, improve the ownership and enforcement of regulations and rules, and satisfy any political good governance requirements like transparency. Negotiations over the complex issues of natural resources management are, however, difficult by nature. Besides, the 
structure, process and outcomes of negotiations and the relationships between these are not fully understood by scientific theory (Yoffe et al. [1]).

The negotiation process and the embedded rules are emphasized while the wider context for successful water basin plan development is neglected. Apart from the negotiation process itself, the negotiation context and the overall conflict characteristics are important. To achieve successful outcomes, collective decision making via negotiation should be prepared and followed up adequately (Figure 1). For each phase of water basin plan development, different computer-based models can be used. These are described as Negotiation Support Systems (NSS) or tools. According to Thiessen et al. [2], models exist as Negotiation Preparation Systems (NIMS) and Negotiation Information Management Systems (NIMS) which consist of Negotiation Process Support System (NPSS) and Negotiation Context Support Systems (NCSS).

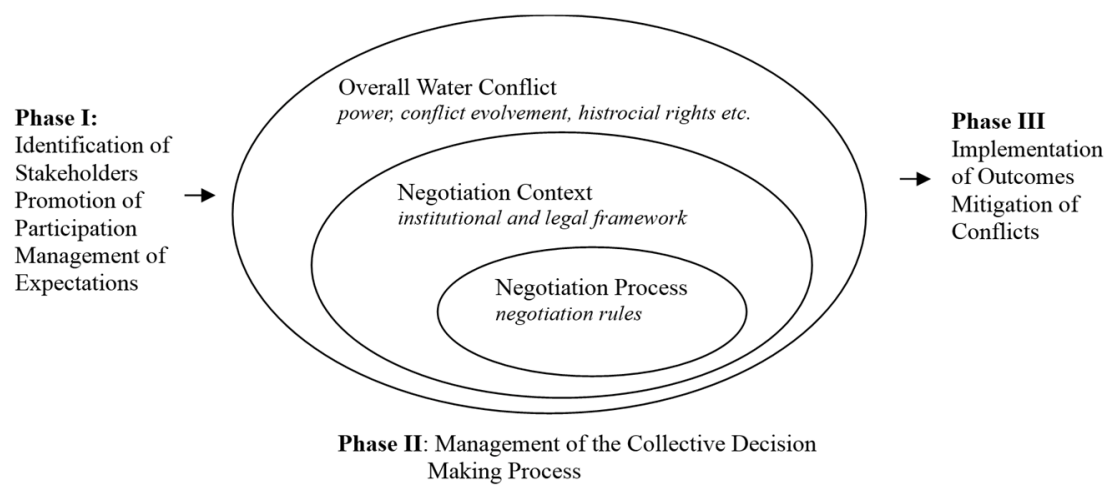

Figure 1: $\quad$ Phases of the Water Basin Plan Development.

\section{Formal negotiation models approaches}

In general, formal negotiation models can be categorized as a part of a game theoretical or complexity-based approach. Within the first approach, cooperative and non-cooperative game theory has been applied to water negotiations. A comprehensive review of cooperative models in water resources is provided by Parrachino et al. [3] and Dinar et al. [4]. In general, cooperative game theory assumes that players maximize their collective welfare. Yet, many water issues, and in fact issues of natural resource management in general, exhibit all the characteristics of a Prisoner's Dilemma game - i.e. cooperation is not a dominant strategy for players and the equilibrium is not Pareto efficient. Formal bargaining models of non-cooperative game theory - each player maximizing his own welfare subject to other players' utility and participation restrictions - have since been used to design the process by which a result is reached. The basic approach in such a bargaining game was introduced in a seminal work of Rubinstein [5] which extended the model of Stahl [6] of a finite horizon alternating model. The limitations of Rubinstein's game - 1) two players, 2) single issue, and 3) resource 
of a known size (certainty) - do not correspond, however, to most real-life negotiation situations. As a result, there have been many model extensions for multiple-issues, and multi-party (multilateral) bargaining. For instance, Chae and Yang [7, 8], Jun [9] and Krishna and Serrano [10] proposed different multi-party negotiation set-ups where a player can exit the negotiation after some level of satisfaction. Furthermore, the role of agenda and sequencing of the negotiation issues have been studied by many authors such as Busch and Horstmann [11], Inderst [12], In and Serrano [13], and Fatima et al. [14]. Finally, uncertainty has been also introduced to the basic non-cooperative game in many different ways uncertain resource size, uncertain disagreement points, unknown identity of the proposing player etc. Sgobbi and Carraro [15] provide in the second chapter of their paper a small literature review on models concerned with uncertainty of the resource size. They conclude that uncertainty makes achieving the equilibrium more difficult and requires more stringent decision rules, such as unanimity. Besides, negotiation is harder and takes longer in the case of uncertainty. In general, there have been many applications of non-cooperative bargaining models to water management issues, see Carraro et al. [16]. Arguably, the dominant model in this field is the multilateral, multi-issue non-cooperative bargaining model of Rausser and Simon [17]. Application of this model exist in Simon et al. [18], Goodhue et al. [19] and Thoyer et al. [20]. There are some important general lessons from such models. For example, shrinking the negotiated policy by excluding a controversial issue leads to loss of mutual gain as the bargaining range becomes smaller. Furthermore, participation is important even for those decision makers who would have very limited political power or access to the process. Special interest groups or minorities can profit from participation as their preferences will be considered by other players if the rules of game are right, e.g. unanimity. Regarding heterogeneity, rules such as requiring the support of enough subgroups and members, and even unanimity, are required. Another alternative is to demand that the different stakeholders select a common spokesman or a representative.

Game theoretical models are based on restrictive assumptions and thus often fail to predict the outcomes of real negotiation processes (e.g. complete rationality and perfect knowledge). Real-life negotiations are characterized by individuals who interact, battle and learn from each other. This realization calls for the use of alternative models which incorporate one part or another of complex reality and simulate the negotiation process on an individual basis. These models represent the new complexity-based approach of study collective decision making. Many of such models are designed as Multi-Agent Systems (MASs) or Agent-Based Models (ABMs). The simulations are based on different groups of agents with different behaviors. An example of such a model is CATCHSCAPE which was developed by Becu et al. [21] or the iterative model of Barreteau et al. [22] based on stakeholder participation in the refinement of the model. Recent models address transboundary water conflicts, Mandi et al. [23], Zagonari and Rossi [24].

While results from complexity-based approaches are mixed, NSS are of great value for analyzing the different scenarios and acceptable outcomes and identifying the potential consequences of different options. They can thus improve 
the agreements or save valuable negotiation time, e.g. the ICAN model of Thiesse et al. [2]. Most importantly, results from game theory and complexity-based models do not exclude each other. There are complementary roles for the two approaches and they can deliver similar results (Dinar et al. [25]).

\section{Basin plan negotiations: the case of the Sebou Basin}

\subsection{The baseline conflict}

Integrated Basin Plans in Morocco (Plan directeur d'aménagement intégré des ressources en eau or PDAIRE) illustrate the conflict dynamics (actors, interests, coalitions, interactions etc.) in the development process of water sharing policies. In order to solve the highly interrelated water problems, Morocco adopted in the late nineties a policy of integrated water resources management. The water law of 1995 constituted a major achievement in this regard. It defined responsibility for water management on national, regional and local levels. Water resources management as such lie within the responsibility of the water department in the Ministry of Energy, Mining, Water and Environment and the Higher Council for Water and Climate. This council is supposed to control and coordinate the work of the ministries and the basin agency, it has however merely a political function. The Basin Water Agencies (agences de bassins hydrauliques, or ABHs) are each responsible for the planning, coordination, implementation and promotion of a decentralized water policy within their river basin.

According to the water law, the river basin agencies should each develop a Basin Plan which evaluates both the quantity and quality of all basin water resources and defines technical, economic and environmental instruments for the development and management of water resources as well as the needed investments and strategies. Such a Basin Plan is set for 20 years and was originally set to be finalized and approved by 2012. Some agencies are still finalizing their plans. Alongside the key role of the Basin Agency, according to the Decree Nr. 205-1534, the development of PDAIRE should include many regional and local actors such as regional and local officials, representatives from water user associations, regional officials from relevant ministries and any consultants needed for technical advice. The Basin Plan should then be approved by the administrative council of the Basin Agency, which is itself composed of representatives of varying interests and presided over by the State Secretary responsible for the water sector. It is then sent for consultation at national level to the relevant ministers before finally arriving with the Higher Council for Water and Climate for final approval before the issuing of a decree by the responsible minister. Table 1 below summarizes the stakeholders involved in the different phases of the negotiation process. The $\mathrm{ABH}$ is an important actor and assisted by donor organizations, consultancy and research teams with high definition power a combined measure based of institutional legitimacy and technical knowledge of the issues. Table 2 categorizes the different stakeholders, issues and decision criteria. 
Table 1: Stakeholders analysis.

\begin{tabular}{|c|c|c|c|c|}
\hline $\begin{array}{l}\text { Negotiation } \\
\text { phase }\end{array}$ & Involved stakeholders & $\begin{array}{l}\text { Power of } \\
\text { definition }\end{array}$ & $\begin{array}{l}\text { Political } \\
\text { power }\end{array}$ & Interest \\
\hline \multirow{6}{*}{ Formulation } & Director and Staff of the ABH & high & low & high \\
\hline & $\begin{array}{c}\text { Officials from Basin Communities } \\
\text { (governors, Walis, council representatives) }\end{array}$ & low & high & low \\
\hline & Representatives of Water User Associations & low & low & high \\
\hline & $\begin{array}{c}\text { Representatives of Professional } \\
\text { Organizations (trade, industry, non- } \\
\text { governmental) } \\
\end{array}$ & low & low & high \\
\hline & $\begin{array}{l}\text { The Prefectural or Provincial Water } \\
\text { Commission }\end{array}$ & low & low & medium \\
\hline & $\begin{array}{c}\text { Representatives of Public Service and } \\
\text { Administration Agencies involved in Water } \\
\text { Issues }\end{array}$ & high & medium & high \\
\hline \multirow[b]{2}{*}{ Revision } & Director and Staff of the $\mathrm{ABH}$ & high & low & high \\
\hline & $\begin{array}{l}\text { Governmental Authorities from affected } \\
\text { sectors }\end{array}$ & medium & high & high \\
\hline \multirow{2}{*}{ Finalization } & Director and Staff of the ABH & high & medium & high \\
\hline & Administrative Council of the ABH & medium & high & high \\
\hline \multirow{2}{*}{ Approval } & Responsible Ministry for Water & high & high & high \\
\hline & The Higher Council for Water and Climate & medium & high & high \\
\hline
\end{tabular}

Table 2: $\quad$ Key parameters.

\begin{tabular}{|c|c|c|}
\hline Interest group & Issue & $\begin{array}{l}\text { Decision criteria/ } \\
\text { performance indicators }\end{array}$ \\
\hline $\begin{array}{l}\text { Urban water } \\
\text { supply }\end{array}$ & $\begin{array}{l}\text { Water availability for urban use/cost of } \\
\text { water/water pollution }\end{array}$ & $\begin{array}{l}\text { Water use fees (abstraction } \\
\text { charges)/pollution fees }\end{array}$ \\
\hline Agriculture & $\begin{array}{l}\text { Water availability for irrigation/ } \\
\text { flood damage/water reservoirs and } \\
\text { harvesting (droughts) }\end{array}$ & $\begin{array}{l}\text { Water use fees/irrigation quotas/ } \\
\text { costs of flood damage/ } \\
\text { investments in reservoirs }\end{array}$ \\
\hline Industry & water availability for industrial use & $\begin{array}{l}\text { Water use fees (abstraction } \\
\text { charges)/pollution fees }\end{array}$ \\
\hline Hydropower & $\begin{array}{l}\text { Dam construction for electricity } \\
\text { production/dam siltation }\end{array}$ & $\begin{array}{l}\text { Investments in hydropower/ } \\
\text { dam quotas and sizes/ } \\
\text { costs of dam siltation }\end{array}$ \\
\hline $\begin{array}{l}\text { Tourism/ } \\
\text { environment/ } \\
\text { recreation }\end{array}$ & $\begin{array}{l}\text { Water conservation/biodiversity/ } \\
\text { pollution of river landscape/ } \\
\text { productivity of nature }\end{array}$ & $\begin{array}{l}\text { Profits/losses to tourism/ } \\
\text { costs of landscape pollution/ } \\
\text { investments in awareness, } \\
\text { conservation and protection }\end{array}$ \\
\hline
\end{tabular}

The water sharing conflicts in Morocco involve many issues. One can illustrate these conflicts using the Sebou Basin which is home to one third of the country's water resources while it covers only $6 \%$ of the national surface area. It contributes 
$30 \%$ to the national potential of surface water resources and $20 \%$ to the groundwater resources. The challenges to the integrated management of the basin's water resources are plenty; and they come along with trade-offs and conflicts, as this study explains later. Firstly, conservation and efficiency is the biggest challenge in light of increasing demand due to rapid economic and high urban population growth. Water availability in Morocco is expected to drop below $500 \mathrm{~m}^{3}$ per capita per year by 2020 . With increasing scarcity, groundwater tables are dropping, especially along the "wadis". In addition, these economic and demographic pressures affect the supply of drinking water and wastewater treatments. Secondly, domestic, industrial and agricultural pollution is a big problem (annual costs of pollution of the basin around US\$ 455 million per year (Sadoff [26])). Thirdly, the overexploitation and degradation of surface and ground water, together with overgrazing and deforestation has led to a degradation and reduction in the surface area of wetland eco-systems. Finally, floods, droughts, siltation and erosion are a big challenge due to irregular rainfall, deforestation and land degradation. The conflicts in the basin are summarized in Figure 3.

Table 3: Water conflicts in Sebou Basin.

\begin{tabular}{c|l}
\hline \hline Conflict & \multicolumn{1}{c}{ Description } \\
\hline $\begin{array}{c}\text { Agricultural vs. } \\
\text { urban sector }\end{array}$ & $\begin{array}{l}\text { Decreasing water availability and high population growth vs. water used } \\
\text { for irrigation; high risk of water degradation through the use of pesticides } \\
\text { in Agriculture; reservoirs for irrigation or water supply. }\end{array}$ \\
\hline $\begin{array}{c}\text { Hydropower vs. } \\
\text { agriculture and } \\
\text { urban water use }\end{array}$ & $\begin{array}{l}\text { Negative effect of dams on water availability for other uses through } \\
\text { evapotranspiration and water diversion; unavailability of water used for } \\
\text { electricity generation for downstream uses; risk of flooding upstream of the } \\
\text { constructed dams. }\end{array}$ \\
\hline $\begin{array}{c}\text { Hydropower vs. } \\
\text { environment }\end{array}$ & $\begin{array}{l}\text { Threat to the minimal water flow for river functionality through dams; } \\
\text { water diversion and wetland loss and drainage downstream through water } \\
\text { diversion; water course dilution downstream of the Fes "wadi" discharge. }\end{array}$ \\
\hline $\begin{array}{c}\text { Polluters vs. } \\
\text { environment }\end{array}$ & $\begin{array}{l}\text { Pollution of water resources by industry especially through olive oil mills is } \\
\text { high, urban domestic pollution through organic matter and high phosphorus } \\
\text { levels and irrigation schemes of intensive farming leaching nitrates into } \\
\text { groundwater while industrial waste. }\end{array}$ \\
\hline \hline
\end{tabular}

\subsection{The Graph Model of conflict resolution}

In this study, the Graph Model will be applied to the conflict setting of the Sebou Basin Plan. Recent applications of the Graph Model relied on the modeling software GMCR II (Graph Model of Conflict Resolution) developed by D.M. Kilgour, K.W. Hipel, L. Fang and X. Peng from the Conflict Analysis Group of the University of Waterloo. For this study, a copy of the software was kindly received from the authors.

The Graph Model represents a decision support system that provides decision makers with valuable advice regarding the context of negotiations. It shifts the focus from the preferences and choices of negotiators of the issues to the outcome of negotiation. Here, it examines the conflict evolution and assesses the likelihood 
of reaching a certain conflict status. The Graph Model of Conflict Resolution was first formulated by Kilgour et al. [27] and then further developed by Fang et al. [28] and Kilgour et al. [29]). It is composed of directed graphs and a set of payoff functions. In order to reach such a graph, the negotiation model has to be constructed with four components: 1) a set of decision makers; 2) a set of states of conflicts; 3) a directed graph; 4) a payoff function. A review of the past applications is provided by Kilgour and Hipel [30].

In order to model the Sebou Basin Plan conflict, decision makers (DMs), actions, states and preferences are to be defined. Table 4 below summarizes the first two steps of modeling (DMs and actions). We assume that the outcome of negotiation relates to the level of environmental protection in the final Basin Plan. The level of environmental protection is a summary measure of three issues: a) rates of water use fees; b) level of pollution charges; and c) degree of environmental standards. The relevant decision makers for the final outcome of the negotiations are derived from the earlier mentioned stakeholder analysis of the conflict (see Table 1).

Table 4: GM: decision makers and options.

\begin{tabular}{|c|c|c|}
\hline DM & Option & Description \\
\hline $\mathrm{ABH}$ & Modify & $\begin{array}{l}\text { Modify the Basin Plan to include a lower level of } \\
\text { environmental protection }\end{array}$ \\
\hline \multirow{3}{*}{$\begin{array}{l}\text { Water Users } \\
\text { (WUs) }\end{array}$} & Delay & Lengthen the negotiation process at the basin level \\
\hline & Accept & $\begin{array}{l}\text { Accept the draft of the } \mathrm{ABH} \text { manager which includes high } \\
\text { level of environmental protection }\end{array}$ \\
\hline & Abort & Leave the negotiation process at the basin level \\
\hline Environmentalists & Insist & $\begin{array}{l}\text { Insist on the Basin Plan with high level of environmental } \\
\text { protection }\end{array}$ \\
\hline $\begin{array}{l}\text { Local } \\
\text { Government (LG) }\end{array}$ & Support & $\begin{array}{l}\text { Support the successful conclusion of the negotiation at the } \\
\text { basin level regardless of the level of environmental } \\
\text { protection }\end{array}$ \\
\hline
\end{tabular}

In this model, the $\mathrm{ABH}$ manager will propose a Basin Plan for negotiation which contains a high level of environmental protection. Still, it will hold for itself the option to modify the plan to include lower standards if necessary. Note that the $\mathrm{ABH}$ is counting on the continuation of financial support from the national government or donor organizations in case of lack of revenues in the future. While any revised draft can only be modified by the $\mathrm{ABH}$ itself, the Water Users (urban, industry, hydropower, agriculture etc.) can either delay, accept, or abort the process. If they choose to abort the process, the model assumes that the whole negotiation will collapse and then the Basin Plan will be referred to national level agencies. This means in reality that ministry-level officials and the Higher Council for Water and Climate will then negotiate for a new, probably watered-down, plan.

Table 5 gives an overview of 17 modeled states of the conflict. A value $\mathrm{N}$ means that this action does not apply (e.g. $\mathrm{N}$ for the $\mathrm{ABH}$ means not to modify its 
Basin Plan draft). The first state for example thus means that the water users will decide to delay the process while all other players will not take actions. In the next steps, the preferences of the stakeholders toward the states are ranked. In this model, it is assumed that the ABH will mostly prefer states where the WUs accept its proposal without modification. Next in preference, it prefers a modification of the draft to a delay or boycott from the WUs. Finally, it prefers to have the support of the LG than not, and to seek the insistence of the environmentalist player not to modify the plan. While the WUs prefer accepting a modified draft to a delay or a boycott of the process, environmentalists most prefer the $\mathrm{ABH}$ not to modify the plan (with their insistence and the support of the LG). If the plan is not modified, the environmentalists prefer a delay of the process with no modification. Yet, they will accept a modification if the alternative is the collapse of the negotiations. Finally, the LG most prefers the acceptance of the WUs with or without modification. They do not want to see the process delayed or aborted.

After modelling the conflict, the analysis starts by running a stability analysis of the conflict states (for solutions under stability analysis see Hipel et al. [31]. The equilibrium result of the Sebou Basin example shows that there are 3 very strong stable states, namely 13,16 and 17 . These refer to three final outcomes of the conflict where: 1) the original draft of the Sebou Basin plan is not modified, the environmentalists insist on the retention of a high level of environmental protection, and thus the WUs will then choose to delay the process while the LG will call for the conclusion of the negotiations without delay (state 13); b) the $\mathrm{ABH}$, with the support of the LG, modifies the draft regardless of the resistance of the environmentalists and, as a result, the WUs will accept the plan (state 16); c) the WUs will abort the negotiation and the plan will be renegotiated at the national level (state 17).

Table 5: GM: conflict states transition.

\begin{tabular}{|c|c|c|c|c|c|c|c|c|c|c|c|c|c|c|c|c|c|c|}
\hline DM & Option & \multicolumn{17}{|c|}{ States } \\
\hline $\mathrm{ABH}$ & Modify & $\mathrm{N}$ & Y & $\mathrm{N}$ & $\mathrm{Y}$ & $\mathrm{N}$ & $\mathrm{Y}$ & $\mathrm{N}$ & Y & $\mathrm{N}$ & $\mathrm{Y}$ & $\mathrm{N}$ & Y & $\mathrm{N}$ & Y & $\mathrm{N}$ & Y & - \\
\hline \multirow{3}{*}{ WUs } & Delay & $\mathrm{Y}$ & $\mathrm{Y}$ & $\mathrm{N}$ & $\mathrm{N}$ & $\mathrm{Y}$ & $\mathrm{Y}$ & $\mathrm{N}$ & $\mathrm{N}$ & Y & $\mathrm{Y}$ & $\mathrm{N}$ & $\mathrm{N}$ & $\mathrm{Y}$ & Y & $\mathrm{N}$ & $\mathrm{N}$ & - \\
\hline & Accept & $\mathrm{N}$ & $\mathrm{N}$ & $\mathrm{Y}$ & $\mathrm{Y}$ & $\mathrm{N}$ & $\mathrm{N}$ & $\mathrm{Y}$ & Y & $\mathrm{N}$ & $\mathrm{N}$ & Y & $\mathrm{Y}$ & $\mathrm{N}$ & $\mathrm{N}$ & $\mathrm{Y}$ & $\mathrm{Y}$ & - \\
\hline & Abort & $\mathrm{N}$ & $\mathrm{N}$ & $\mathrm{N}$ & $\mathrm{N}$ & $\mathrm{N}$ & $\mathrm{N}$ & $\mathrm{N}$ & $\mathrm{N}$ & $\mathrm{N}$ & $\mathrm{N}$ & $\mathrm{N}$ & $\mathrm{N}$ & $\mathrm{N}$ & $\mathrm{N}$ & $\mathrm{N}$ & $\mathrm{N}$ & $\mathrm{Y}$ \\
\hline Env.* & Insist & $\mathrm{N}$ & $\mathrm{N}$ & $\mathrm{N}$ & $\mathrm{N}$ & $\mathrm{Y}$ & Y & $\mathrm{Y}$ & Y & $\mathrm{N}$ & $\mathrm{N}$ & $\mathrm{N}$ & $\mathrm{N}$ & $\mathrm{Y}$ & Y & $\mathrm{Y}$ & $\mathrm{Y}$ & - \\
\hline LG & Support & $\mathrm{N}$ & $\mathrm{N}$ & $\mathrm{N}$ & $\mathrm{N}$ & $\mathrm{N}$ & $\mathrm{N}$ & $\mathrm{N}$ & $\mathrm{N}$ & $\mathrm{Y}$ & $\mathrm{Y}$ & $\mathrm{Y}$ & $\mathrm{Y}$ & $\mathrm{Y}$ & $\mathrm{Y}$ & $\mathrm{Y}$ & $\mathrm{Y}$ & - \\
\hline \multicolumn{2}{|c|}{$\begin{array}{c}{ }^{*} \text { Env. }= \\
\text { Environmentalists }\end{array}$} & 1 & 2 & 3 & 4 & 5 & 6 & 7 & 8 & 9 & 10 & 11 & 12 & 13 & 14 & 15 & 16 & 17 \\
\hline
\end{tabular}


The results from this analysis can now be used to construct the final Graph Model (Figure 2) which depicts the so-called 'reachable states' for each player. This graph should be interpreted considering the equilibrium states and the preferences of the players over the different states. It is now clear why states 13 , 16 and 17 are considered strongly stable states, since no player can move from there into a better state. For example, state 16 is preferred by both the ABH and WUs to 13 since both prefer modifying the plan in order to ensure the acceptance of the WUs (state 16) to not modifying it and risking the process being delayed by the WUs (state 13). However, once arrived at state 13, state 16 is not reachable from there, while any unilateral move by any player to a reachable state would not be beneficial to that player. If the $\mathrm{ABH}$ unilaterally decides to accept modifying the plan (transition from state 13 to state 14), it loses, as there is no guarantee that the modified plan will be accepted by the WUs.



Figure 2: GM: conflict states transition.

The Graph Model of the conflict also allows us to understand possible coalitions in the evolvement of the conflict. In the previous example, although state 13 is highly stable and resistant to any unilateral moves, it is also amenable to the formation of coalitions. Once in state 13 , the ABH and WUs can build a coalition for the $\mathrm{ABH}$ to change its decision and modify the plan (transition from 13 to 14 ) while the WUs will move to accept it (transition from 14 to 16). Thus, both of them reach a more preferable state. Of course, this is not possible for states 16 and 17. In state 16 , only the environmentalists can make a move to stop their insistence to the original plan before modification (transition from 16 to 12), yet this is not in their interest.

If we consider state 1 , which is represented by low stakeholder participation and delay, as the status quo of the process, the important role and trade-offs of the stakeholders become clear. Indeed, the Graph Model provides useful information for all stakeholders on their options and their consequences. If the ultimate goal is 
to see the negotiations succeed with at least some measure of environmental protection, the $\mathrm{ABH}$ can play an important role through its feasible coalitions with the WUs and the local government. If successful, the process might result in a dampened outcome in terms of environmental protection; yet, for most stakeholders, this is better than a chronic delay or a failure of negotiations.

\section{Conclusions}

Insights from formal negotiations models of collective decision-making deliver useful insights like increase of participation, the inclusion of controversial topics, participation, address heterogeneity of groups through spokespersons etc. Current basin plan drafts in Morocco largely focus on resource quantification and use. Although this is good to address the issue of uncertainty, more participation in a negotiation setting is needed. Collective decision-making in watershed management in Morocco is institutionalized but the implementation is largely adhoc. Basin plan development is characterized by delay and weak participation. The outcome is often suboptimal in terms of clear regulations, investment plans and responsibilities. Basin agencies are well-advised to adopt a bottom-up approach to basin plan development through negotiation. Decision support systems can ease the negotiation process, and add an argument for negotiation.

Overall, the Graph Model explains the delay in the Basin Plan process in Sebou and gives real predictions on coalitions and outcomes. These predictions might yet benefit the state of water resources in the basin as a whole. With actors such as agriculture and industry currently favoring the status quo or a dampened outcome of the process, the process will probably be concluded with a minor success. This might be not useful and would not be the best outcome, considering the needs and rights of future generations. In any case, governmental actors such as the High Council or similar institutions should be more active in the process in order to reach a negotiated outcome which lives up to the expectations of current and future generations. In particular, the local government needs to be more involved as it ultimately pays the costs of any failures of the process. Besides, the ABHs in Morocco lack financial revenues and thus have a stake in the negotiation and an interest in collecting high water use and pollution charges.

\section{References}

[1] Yoffe, S., Fiske, G., Giordano, M., Larson, K., Stahl, K. S, \& Wolf, A. T., Geography of International Water Conflict and Cooperation: Data Sets and Applications. Water Resources Research, 40 (5), pp. 1-12, 2004.

[2] Thiesse, E. M., Loucks, D. P., \& Stedinger, J. R., Computer Assisted Negotiation of Water Resource Conflicts. Group Decision and Negotiations 7, pp. 109-129, 1998.

[3] Parrachino, I., Dinar, A., \& Patrone, P., "Cooperative Game Theory and its Application to Natural, Environmental, and Water Resource Issues: 3. Application to Water Resources”. Policy Research Working Paper 4074, World Bank, 2006. 
[4] Dinar, A., Ratner, A., \& Yaron, D., Evaluating Cooperative Game Theory in Water Resources. Theory and Decision, 32, pp.1-20, 1992.

[5] Rubinstein, A., Perfect Equilibrium in a Bargaining Model. Econometrica, 50, pp. 97-110, 1982.

[6] Stahl, I., Bargaining Theory. Stockholm: the Economic Research Institute at the Stockholm School of Economics, 1972.

[7] Chae, S. \& Yang, A., The Unique Perfect Equilibrium of an N-Person Bargaining Game. Economic Letters, 28, pp. 221-223, 1988.

[8] Chae, S. \& Yang, A., A N-Person Pure Bargaining Game. Journal of Economic Theory, 62: pp. 86-102, 1994.

[9] Jun, B.H., "A Structural Consideration on 3-Person Bargaining”, Chapter III in Essays on Topics in Economic Theory. Ph.D. Thesis, Department of Economics, University of Pennsylvania, 1987.

[10] Krishna, V. \& Serrano, R., A Model of Multilateral Bargaining. Review of Economic Studies, 63, pp. 61-80, 1996.

[11] Busch, L. A. \& Horstmann, I., Signaling Via Agenda in Multi-Issue Bargaining with Incomplete Information. Economic Theory, 13/3, pp. 561$575,1999$.

[12] Inderst, R., Multi-Issue Bargaining with Endogenous Agenda. Games and Economic Behavior, 30, pp. 64-82, 2000.

[13] In, Y., \& Serrano, R., Agenda Restrictions in Multi-Issue Bargaining (II): Unrestricted Agendas. Economic Letters, 79, 325-331, 2003.

[14] Fatima, S., Wooldrige, M., \& Jennings, N.R., "Optimal Agendas for MultiIssue Negotiation", Proceedings of the 2003 second international joint conference on autonomous agents and multi-agent systems, pp. 129-136, 2003.

[15] Sgobbi, A. \& Carraro, C., Modelling Negotiated Decision Making in Environmental and Natural Resource Management, Automatica 44, pp. 1488-1503, 2008

[16] Carraro, C., Marchiori, C., \& Sgobbi, A., "Applications of Negotiation Theory to Water Issues", Working Paper 656.06, Fondazione Eni Enrico Mattei, 2005.

[17] Rausser, G. \& Simon, L., "A Non Cooperative Model of Collective Decision Making: A Multilateral Bargaining Approach", Department of Agricultural and Resource Economics, University of California, 1999.

[18] Simon, L., Goodhue, R., Rausser, G., Thoyer, S., Morardet, S., \& Rio, P., "Structure and Power in Multilateral Negotiations: An Application to French Water Policy", paper presented at 6th Meeting of Game Theory and Practice, Zaragoza, Spain 10-12 July, 2006.

[19] Goodhue, R., Rausser, G., Simon, L., \& Thoyer, S., Negotiating over the Allocation of Water Resources: The Strategic Importance of Bargaining Structure. In Dinar, A, Albiac, J., Sanchez-Soriano J. (Eds.) Game Theory and Policy Making in Natural Resources and the Environment. pp. 132-54. New York: Routledge, 2008. 
[20] Thoyer, S., Morardet, S., Rio, P., Simon, L., Goodhue, R., \& Rausser, G., A Bargaining Model to Stimulate Negotiations between Water Users. Journal of Artificial Societies and Social Simulation, 4 (2), 2001.

[21] Becu, N., Perez, P., Walker, A., Barreteau, O., \& Le Page, C., Agent Based Simulation of a Small Catchment Water River Management in Northern Thailand: Description of the CATCHSCAPE model. Ecological Modeling, 170, pp. 319-331, 2003.

[22] Barreteau, O., Garin, P., Dumontier, A., \& Arami, G., Agent Based Facilitation of Water Allocation: Case Study in the Drome River Valley. Group Decision and Negotiations 12, pp. 441-4613, 2003.

[23] Mandi, K., Rouhani, O. M., Mirchi A., Gholizadeh, S., A Negotiation Support System for Resolving an International Transboundary Natural Conflict, Environmental Modelling \& Software, Vol. 51, P. 240-249, 2014.

[24] Zagonari, F., Rossi, C. A Negotiation Support System for Disputes between Iraq and Turkey over the Tigris-Euphrates Basin, Journal of Hydrology, Vol. 514, pp. 65-84, 2014.

[25] Dinar, A., Farolfi, S., Patrone, P., \& Rowntree, K., To Negotiate or to Game Theorize: Evaluating Water Allocation Mechanisms in the Kat Basin, South Africa. In A. Dinar, J. et al. Game Theory and Policy Making in Natural Resources and the Environment. pp. 85-111, London: Routledge, 2008.

[26] Sadoff, C. W., "The Price of Dirty Water: Pollution Costs in the Sebou Basin”, Environmental Economic Series, Paper No. 039, World Bank, 2006.

[27] Kilgour, D. M, Hipel, K. W., \& Fang, L., The Graph Model for Conflicts. Automatica 23(1), pp. 41-55, 1987.

[28] Fang, L., Hipel, K.W., \& Kilgour, D. M., Interactive Decision Making: The Graph Model for Conflict Resolution. New York: Wiley, 1993.

[29] Kilgour, D. M, Hipel, K. W., \& Fang, L., Negotiation Support Using the Graph Model for Conflict Resolution. Group Decision and Negotiations, 3, pp.169-185, 1994.

[30] Kilgour, D. M. \& Hipel, K. W., The Graph Model for Conflict Resolution. Group Decision and Negotiations, 14, pp. 441-460, 2005.

[31] Hipel, K. W., Fang, L., \& Kilgour, D. M., A Formal Analysis of the CanadaU.S. Softwood Lumber Dispute. European Journal of Operational Research 46(2), pp. 235-246, 1990. 